OPEN ACCESS

Edited by:

Fei Chen,

Wayne State University, United States

Reviewed by:

Amit K. Tiwari,

University of Toledo, United States

Chunming Wang,

University of Macau, China

*Correspondence:

Weiguo Feng

Fengwg@wfmc.edu.cn

Zhe-Sheng Chen

Chenz@stjohns.edu

Specialty section:

This article was submitted to

Molecular and Cellular Oncology,

a section of the journa

Frontiers in Cell and Developmental

Biology

Received: 02 July 2020 Accepted: 11 August 2020

Published: 27 August 2020

Citation:

Dong $X-D$, Zhang $M, M a X$ Wang J-Q, Lei Z-N, Teng Q-X, Li Y-D, Lin L, Feng $W$ and Chen Z-S (2020)

Bruton's Tyrosine Kinase (BTK) Inhibitor RN486 Overcomes ABCB1-Mediated Multidrug Resistance in Cancer Cells. Front. Cell Dev. Biol. 8:865. doi: 10.3389/fcell.2020.00865

\section{Bruton's Tyrosine Kinase (BTK) Inhibitor RN486 Overcomes ABCB1-Mediated Multidrug Resistance in Cancer Cells}

\begin{abstract}
Xing-Duo Dong ${ }^{1}$, Meng Zhang, ${ }^{1,2}$, Xiubin Ma $^{3}$, Jing-Quan Wang ${ }^{1}$, Zi-Ning Lei', Qiu-Xu Teng ${ }^{1}$, Yi-Dong Li ${ }^{1}$, Lusheng Lin ${ }^{3}$, Weiguo Feng ${ }^{1,4 *}$ and Zhe-Sheng Chen ${ }^{1 *}$

${ }^{1}$ Department of Pharmaceutical Sciences, College of Pharmacy and Health Sciences, St. John's University, Queens, NY, United States, ${ }^{2}$ First Clinical College, Shandong University of Traditional Chinese Medicine, Jinan, China, ${ }^{3}$ Cell Research Center, Shenzhen Bolun Institute of Biotechnology, Shenzhen, China, ${ }^{4}$ College of Bioscience and Technology, Weifang Medical University, Weifang, China
\end{abstract}

Overexpression of ATP-binding cassette subfamily B member 1 (ABCB1) remains one of the most vital factors leading to multidrug resistance (MDR). It is important to enhance the effect and bioavailability of chemotherapeutic drugs that are substrates

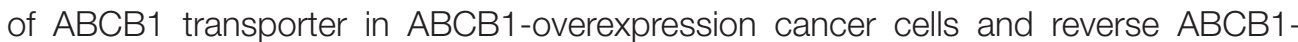
mediated MDR. Previous, we uncovered that the Bruton's tyrosine kinase (BTK) inhibitor ibrutinib is a potent reversal agent to overcomes paclitaxel resistance in ABCB1overexpressing cells and tumors. In this study, we explored whether RN486, another BTK inhibitor, was competent to surmount ABCB1-mediated MDR and promote relevant cancer chemotherapy. We found that RN486 significantly increased the efficacy of paclitaxel and doxorubicin in both drug-selected carcinoma cells and transfected cells overexpressing ABCB1. Mechanistic studies indicated that RN486 dramatically attenuated the drug efflux activity of $A B C B 1$ transporter without altering its expression level or subcellular localization. The ATPase activity of ABCB1 transporter was not affected by low concentrations but stimulated by high concentrations of RN486. Moreover, an interaction between RN486 with ABCB1 substrate-binding and inhibitor binding sites was verified by in silico docking simulation. The results from our study suggest that RN486 could be a reversal agent and could be used in the novel combination therapy with other antineoplastic drugs to conquer MDR-mediated by ABCB1 transporter in clinics.

Keywords: RN486, Bruton's tyrosine kinase inhibitor, multidrug resistance, ATP-binding cassette transporter, ABCB1

\section{INTRODUCTION}

Uncovering the best treatment for cancer is still challenging since cancer is one of the most dreadful diseases for the last several decades (Roy and Saikia, 2016). Chemotherapy is one of the primary and vital treatments to fight with a variety of cancers (Zhang et al., 2015). However, the presence of multidrug resistance (MDR) decreases the efficacy of anticancer drugs 
(Wu et al., 2011). It has been found that the mechanisms leading to MDR include enhancing drug efflux activity, advanced DNA damage repair functions, altered drug metabolism or reduced apoptosis (Gottesman et al., 2002; Eckford and Sharom, 2009). Among these mechanisms, the overexpression of adenosine triphosphate (ATP)-binding cassette (ABC) transporters resulted in increasing drug efflux is considered to be the predominant factor (Kathawala et al., 2015a; Kartal-Yandim et al., 2016).

The $\mathrm{ABC}$ transporters located on the cell membrane are efflux proteins and play important physiological and pharmacological roles (Dassa and Bouige, 2001). Currently, 49 distinct ABC transporters in which 48 of them are functional are split into seven subfamilies from ABCA to ABCG in humans (Stavrovskaya and Stromskaya, 2008; Eckford and Sharom, 2009). ABCB1 (P-glycoprotein, P-gp; multidrug resistance 1, MDR1), ABCG2 (breast cancer resistance protein, BCRP; mitoxantrone resistance, $\mathrm{MXR}$ ), and $\mathrm{ABCC} 1$ (multidrug resistance protein 1, MRP1) are the most important $\mathrm{ABC}$ transporters and the overexpression of them render emergence of MDR in cancer cells (Dean, 2009; Li et al., 2016). ABCB1, as one of the major MDR contributors, is the most well-known and best characterized in the $\mathrm{ABC}$ transporter family. It was firstly discovered in 1976 and has been studied extensively (Juliano and Ling, 1976). It is generally distributed in bone marrow, blood-brain barrier (BBB), placenta, gut mucosa, liver, and kidney where it protects organ by preventing toxins from entering vital organs or facilitating the process of eliminating toxins via efflux (Sparreboom et al., 1997; Schinkel, 1999). Nevertheless, the overexpression of ABCB1 also results in reducing the intracellular accumulation of a wide variety of chemotherapeutic substrates including taxanes, vinca alkaloids, and anthracyclines (Tiwari et al., 2011; Schinkel and Jonker, 2012; Sodani et al., 2012). Thus, it is extremely urgent to investigate or develop novel compounds as inhibitors of $\mathrm{ABCB} 1$ to overcome the related MDR.

Bruton's tyrosine kinase (BTK), a $77 \mathrm{kDa}$ non-receptor tyrosine kinase, is a group of distinct cell surface receptors, especially B-cell antigen receptors (Mohamed et al., 2009). Since BTK regulates the activation, proliferation, maturation, differentiation and survival of B-cells, it has emerged as a novel molecular target in the treatment of leukemia and lymphoma of some B-cells (Mohamed et al., 2009; Singh et al., 2018). Furthermore, the study in prostate cancer cohort indicated that BTK knockdown selectively inhibited the growth of prostate cancer cells (Guo et al., 2014). In BTK highly expressed primary neuroblastoma samples, BTK inhibitor acalabrutinib elicited remarkable effect on inhibition of neuroblastoma tumorigenesis (Pikatan et al., 2020). New BTK inhibitors developed by indole derivatives also appeared for related cancer treatments (Rathi et al., 2017). Notably, BTK inhibitors had multiple off-target effects, especially ibrutinib (Gavriatopoulou et al., 2020; Metzler et al., 2020). Currently, ibrutinib, which was approved by Food and Drug Administration (FDA) for treating mantle cell lymphoma (MCL) and chronic lymphocytic leukemia (CLL) (Zhang et al., 2017), has been reported to have significant effect to improve the efficacy of chemotherapeutic drugs transported by $\mathrm{ABCB} 1$ transporter in $\mathrm{ABCB} 1$-overexpressing cells (Zhang et al., 2017).
Another BTK inhibitor, RN486, is a selective, and reversible inhibitor of BTK. It binds to the enzyme potently and competitively. In addition, RN486 is a preclinical drug and has the potential therapeutic benefits in treating rheumatoid arthritis (RA) in rodents and RA synovial tissue explants (Xu et al., 2012; Hartkamp et al., 2015). Moreover, in mouse models, RN486 attenuates systemic lupus erythematosus (SLE) by inhibiting B-cell activation, reducing the secretion of IgG antidouble-stranded DNA (anti-dsDNA), and impacting the effector function of autoantibodies (Mina-Osorio et al., 2013).

In this study, we evaluate whether the BTK inhibitor, RN486, has similar effect as ibrutinib to enhance the tumor suppression activity of chemotherapeutic agents and overcome ABCB1mediated MDR.

\section{MATERIALS AND METHODS}

\section{Chemicals}

RN486 was a gift from Chemie Tek (Indianapolis, IN, United States). Dulbecco's modified Eagle's Medium (DMEM), fetal bovine serum (FBS), penicillin/streptomycin, and $0.25 \%$ trypsin were obtained from Corning Incorporated (Corning, NY, United States). The monoclonal antibody of GAPDH (catalog number MA5-15738, lot number SA247966, clone GA1R), Alexa Fluor 488 conjugated goat anti-mouse IgG secondary antibody, bicinchoninic acid (BCA) assay Reagents, and enhanced chemiluminescence (ECL) Western blotting substrate were products from Thermo Fisher Scientific Inc. (Rockford, IL). The compounds cisplatin, colchicine, paclitaxel, doxorubicin, verapamil, the monoclonal antibodies for ABCB1 (catalog number P7965, lot number 067M4761V, clone F4), dimethyl sulfoxide (DMSO), 3-(4,5dimethylthiazolyl)-2,5-diphenyltetrazolium bromide (MTT), Triton X-100, 4',6-diamidino-2-phenylindole (DAPI), and paraformaldehyde, were purchased from Sigma-Aldrich (St. Louis, MO, United States). Horseradish peroxide (HRP)conjugated rabbit anti-mouse IgG secondary antibody (catalog number 7076S, Lot number 32) were obtained from Cell Signaling Technology Inc. (Danvers, MA, United States). Bovine Serum Albumin (BSA) and $10 \mathrm{X}$ phosphate buffer solution (PBS) were gained from VWR chemicals, LLC (Solon, OH, United States). $\left[{ }^{3} \mathrm{H}\right]$-paclitaxel $(15 \mathrm{Ci} / \mathrm{mmol})$ was bought from Moravek Biochemicals, Inc. (Brea, CA, United States). All the other chemicals were purchased from Sigma Chemical Co. (St. Louis, MO, United States).

\section{Cell Lines and Cell Culture}

The colchicine-induced ABCB1-overexpressing resistant cell line $\mathrm{KB}-\mathrm{C} 2$ and its parental cell line, human epidermoid carcinoma KB-3-1, were used in our study (Wang et al., 2014). HEK293/pcDNA3.1, HEK293/ABCB1 were transfected human embryonic kidney HEK293 cells carried empty pcDNA3.1 vector and the vector containing $\mathrm{ABCB} 1$ gene, respectively. G418 $(2 \mathrm{mg} / \mathrm{ml}$ ) was used to select transfected cells (Kathawala et al., 2015b). DMEM medium containing 10\% fetal bovine serum and $1 \%$ penicillin/streptomycin was prepared to culture all the 
mentioned cells with the condition of $37^{\circ} \mathrm{C}$ incubator having $5 \% \mathrm{CO}_{2}$. All cells were used in experiments when they formed adherent monolayer with $60-80 \%$ cell confluence.

\section{Cytotoxicity and Reversal Experiments}

The MTT assay was used in cell viability and reversal experiments as previously described (Lyall et al., 1987). The concentration of $5 \times 10^{3}$ cells per well were seeded with $160 \mu \mathrm{l}$ medium in 96well plates and the plate was maintained in incubator overnight. In cytotoxicity experiment, the diluted concentrations of reversal reagent RN486 were administrated into different wells. In reversal experiment, various concentrations of RN486 were added $2 \mathrm{~h}$ prior to the addition of diluted concentrations of traditional chemotherapeutic drugs to specific wells. After incubation of $68 \mathrm{~h}, 20 \mu \mathrm{l} \mathrm{MTT}$ solution $(4 \mathrm{mg} / \mathrm{ml}$ ) was added to all the wells following further incubation of cells for $4 \mathrm{~h}$. The supernatant of each well was discarded and $100 \mu \mathrm{l}$ of DMSO was added to dissolve the formazan crystals. By using a UV/Vis Microplate Spectrophotometer (Fisher Sci., Fair Lawn, NJ, United States), the light absorbance was detected with $570 \mathrm{~nm}$ wavelength. $\mathrm{IC}_{50}$ value which is the concentration for $50 \%$ inhibition of cell viability was calculated as previously described (Ji et al., 2019a). Verapamil was used as a positive control inhibitor of ABCB1 transporter. Non-substrate drug of ABCB1, cisplatin, was used as a negative control chemotherapeutic drug in reversal experiment.

\section{Immunoblot Analysis}

Based on the MTT assay, the concentration $3 \mu \mathrm{M}$ of RN486 was used to treat the resistant cells with different time periods $(0,24,48$, and $72 \mathrm{~h})$. The parental cells without RN486 were also incubated for $72 \mathrm{~h}$. Then all the cells were lysed after twice washing of ice-cold PBS. The protein concentration was determined by BCA Protein Assay Kit (Thermo Scientific, Rockford, IL, United States). Same amounts of protein were loaded in sodium dodecyl sulfate polyacrylamide gel following the transfer of protein from the gel onto polyvinylidene fluoride (PVDF) membranes. To eliminate non-specific protein binding, membrane blocking was performed in TBST (Tris-buffered saline, $0.1 \%$ Tween 20 ) buffer with $5 \%$ non-fat milk for $2 \mathrm{~h}$ at room temperature. Afterward, the primary antibodies of ABCB1 (1:1000) and GAPDH (1:1000) were used to immunoblot against the membrane overnight at $4^{\circ} \mathrm{C}$. The HRP-conjugated secondary antibody $(1: 1000)$ was applied against primary antibodies for $2 \mathrm{~h}$ at room temperature after the membrane was washed with TBST buffer. Next, three times washing of membrane was conducted in TBST buffer with the interval of $5 \mathrm{~min}$. Chemiluminescent signal was obtained by the reaction between luminescent substrate ECL and secondary antibody. Protein quantification was analyzed by using ImageJ software.

\section{Immunofluorescence Assay}

The immunofluorescence assay was carried out following the previous description (Cai et al., 2020). KB-3-1 and KB-C2 cells $\left(1 \times 10^{4}\right)$ were seeded in 24 -well plates followed by overnight culture at $37^{\circ} \mathrm{C}$. Then, the cells were incubated with or without $3 \mu \mathrm{M}$ RN486 at the different time periods $(0,24,48$, and
$72 \mathrm{~h}$ ) in designated wells. After being washed twice with icecold PBS, the fixation of cells was performed in wells by $4 \%$ formaldehyde for $15 \mathrm{~min}$. The $0.25 \%$ Triton X-100 was used to treat cells for $15 \mathrm{~min}$ followed by the incubation with BSA (6\% with PBS) for $1 \mathrm{~h}$ of blocking. Cells were incubated with primary monoclonal antibodies of ABCB1 (1:1000) overnight at $4^{\circ} \mathrm{C}$. Later, Alexa Fluor 488 conjugated IgG secondary antibody (1:1000) was added in wells for $2 \mathrm{~h}$ in dark after the cells getting washed with PBS. The nuclei of cells were counterstained by DAPI solution. Fluorescence images were captured by Nikon TE-2000S microscope (Nikon Instruments Inc., Melville, NY, United States).

\section{$\left[{ }^{3} \mathrm{H}\right]$-Paclitaxel Accumulation and Efflux Assay}

As previously described (Fan et al., 2018; Cui et al., 2019b), accumulation and efflux assays were conducted to explore the antagonistic mechanism of RN486 by using a substrate of ABCB1, $\left[{ }^{3} \mathrm{H}\right]$-paclitaxel. For $\left[{ }^{3} \mathrm{H}\right]$-paclitaxel accumulation assay, KB-31 and KB-C2 cells with concentration of $1 \times 10^{5}$ per well were inoculated into 24 -well plates. On the next day, various concentrations of RN486 $(0,1$, and $3 \mu \mathrm{M})$ and verapamil $(3 \mu \mathrm{M})$ were added separately in both parental KB-3-1 and its resistant KB-C2 cell lines $2 \mathrm{~h}$ before adding $\left[{ }^{3} \mathrm{H}\right]$-paclitaxel. After culturing the cells with $\left[{ }^{3} \mathrm{H}\right]$-paclitaxel for $2 \mathrm{~h}$, trypsin-EDTA was used to digest the cells and the cells were collected into $5 \mathrm{ml}$ scintillation solution. For $\left[{ }^{3} \mathrm{H}\right]$-paclitaxel efflux assay, distinct concentrations of $\operatorname{RN} 486(0,1$, and $3 \mu \mathrm{M})$ and verapamil $(3 \mu \mathrm{M})$ were added $2 \mathrm{~h}$ before $\left[{ }^{3} \mathrm{H}\right]$-paclitaxel. After culturing $\left[{ }^{3} \mathrm{H}\right]$-paclitaxel, the supernatant was discarded and medium was added with the absence or presence of inhibitor. Finally, cells were collected at 0 , 30, 60, and 120 min. By using Packard TRI-CARB1 190'A liquid scintillation analyzer (Packard Instrument, Downers Grove, IL, United States), the radioactivity of the samples at different time points were collected (Wang J. et al., 2020).

\section{ATPase Assay}

The ATPase assay of ABCB1 transporter was carried out using PREDEASY ATPase assay kit (TEBU-BIO nv, Boechout, Belgium) as previously described (Cui et al., 2019b). Membrane $(10 \mu \mathrm{g})$ was incubated with or without sodium orthovanadate $(0.3 \mathrm{mM})$ in assay buffer. Then, RN486 (0-40 $\mu \mathrm{M})$ was added. The reaction was initiated once adding $5 \mathrm{mM}$ of ATP and terminated by adding $5 \%$ SDS solution. The amount of inorganic phosphate $(\mathrm{Pi})$ was determined with a colorimetric method as described before (Ji et al., 2019b). Light absorbance was measured at $880 \mathrm{~nm}$ using a spectrophotometer.

\section{Molecular Docking of RN486 With Human ABCB1 Models}

The RN486 3-D structure was established for docking simulation with a human ABCB1 model as previously described (Wang J. Q. et al., 2020). Human ABCB1 protein model 6QEX (ligand: paclitaxel, an ABCB1 ATPase stimulator) and 6QEE (ligand: zosuquidar, an ABCB1 ATPase inhibitor) were acquired from RCSB Protein Data Bank. Both models are inward-facing human 
ABCB1 with a resolution of $3.6 \AA$ (6QEX) or $3.9 \AA$ (6QEE) (Alam et al., 2019). AutoDock Vina (version 1.1.2) was used for docking calculations (Vina, 2010). Hydrogen atoms and partial charges were added using AutoDock Tools (ADT, version 1.5.4). Docking grid center coordinates were determined from the bound ligands provided in PDB files. The default settings were used for receptor/ligand preparation and docking. Based on the sorted affinity score $(\mathrm{kcal} / \mathrm{mol})$, the top-scoring pose was further analyzed and visualized.

\section{Statistics}

The data are presented as the mean \pm SD. One-way analysis of variance (ANOVA) followed by Dunnett's post hoc test was used to analyze the significance. When $P<0.05$, it is considered statistically significant difference between treatment groups with corresponding control group. All experiments were repeated at least three times.

\section{RESULTS}

\section{RN486 Enhanced the Efficacy of Anti-cancer Drugs in ABCB1-Overexpressing Cancer Cells}

The cytotoxicity of RN486 was firstly tested in various cell lines. The non-toxic concentrations $(0.3,1$, and $3 \mu \mathrm{M})$ that less than $\mathrm{IC}_{20}$ (concentration for $20 \%$ inhibition) after $72 \mathrm{~h}$ incubation were selected according to the results (Figure 1). The reversal data were shown in Table 1. Compared to parental KB-3-1 cells, the $\mathrm{IC}_{50}$ values of doxorubicin and paclitaxel were much higher in the resistant KB-C2 cells, which rendered high resistance-fold, by 101.4- and 707.3-fold, respectively. The $\mathrm{IC}_{50}$ values of doxorubicin and paclitaxel in KB-C2 cells were dramatically decreased with the addition of RN486 in a concentration-dependent manner. RN486 had greater reversal effect than verapamil at the same concentration $(3 \mu \mathrm{M})$. The reversal experiments on the transfected HEK293/pcDNA3.1 and HEK293/ABCB1 cells were conducted to confirm that RN486 improves the efficacy of anticancer drugs by the interaction with ABCB1 transporter. As shown in Table 2, RN486 re-sensitized the ABCB1-overexpressing cell line HEK293/ABCB1 compared with the vector control cell line HEK293/pcDNA3.1. In this study, the well-known ABCB1 inhibitor verapamil was served as positive control of the reversal reagent and cisplatin was used as negative control of anticancer drug since it was not a substrate of ABCB1.

\section{RN486 Did Not Significantly Affect the Expression Level of ABCB1 and Subcellular Localization in ABCB1-Overexpressing Cancer Cells}

From the above MTT assay, RN486 indeed antagonized ABCB1-mediated MDR. The possible reversal mechanism may include down-regulation of the protein or change the localization of protein. We carried out Western blotting and immunofluorescence assay to look into these possibilities. The optimal concentration of RN486 at $3 \mu \mathrm{M}$ was selected in both assays and KB-3-1 cells were used as negative control cell line. It was found that the expression level of $\mathrm{ABCB} 1$ in $\mathrm{KB}-\mathrm{C} 2$ cells did not change significantly with these treatments after being incubated for different time $(0,24$, 48, and $72 \mathrm{~h}$ ) (Figure 2A). Moreover, our results showed that the expression of $\mathrm{ABCB} 1$ protein remained on the cell membrane of KB-C2 cells without trans-localizing to the cytoplasm or other organelles during 24-72 h treatment with RN486 (Figure 2B). These results indicated that RN486 reversed $A B C B 1-$ mediated $M D R$ are not related to the down-regulation of $\mathrm{ABCB} 1$ protein or alteration of its subcellular localization.

\section{RN486 Increased the Intracellular Accumulation of $\left[{ }^{3} \mathrm{H}\right]$-Paclitaxel in ABCB1-Mediated MDR Cancer Cells}

To further evaluate the function of RN486 when it was used together with an anticancer drug, we performed the $\left[{ }^{3} \mathrm{H}\right]$ paclitaxel accumulation assay in KB-3-1 and KB-C2 cells. The concentrations of $\left[{ }^{3} \mathrm{H}\right]$-paclitaxel were accumulative from the induction of it to the time of cell detachment. As shown in Figure 3A, RN486 significantly increased the intracellular accumulation of $\left[{ }^{3} \mathrm{H}\right]$-paclitaxel in the drug resistant $\mathrm{KB}-\mathrm{C} 2$ cells, especially when the concentration was $3 \mu \mathrm{M}$. In addition, the increased levels of $\left[{ }^{3} \mathrm{H}\right]$-paclitaxel accumulation in cells were more significant in those treated with both 1 and $3 \mu \mathrm{M}$ RN486 (2.17 and 2.80 pmol per $10^{6}$ cells) compared to those treated with $3 \mu \mathrm{M}$ verapamil $\left(1.76 \mathrm{pmol}\right.$ per $10^{6}$ cells) in resistant KB-C2 cells. RN486 did not significantly interfere the accumulation of $\left[{ }^{3} \mathrm{H}\right]$-paclitaxel in parental KB-3-1 cells $\left(0.12\right.$ pmol per $10^{6}$ cells $)$. These results suggested that RN486 may inhibit the function of ABCB1 transporter which leads to increased drug accumulation inside the cells.

\section{RN486 Blocked the Efflux Activity Mediated by ABCB1 Transporter in ABCB1-Overexpressing Cancer Cells}

The efflux assay was performed after accumulation assay to investigate the antagonization mechanism of RN486 in cancer cells. The concentrations of $\left[{ }^{3} \mathrm{H}\right]$-paclitaxel in the cells were transient at different time points. It was found that RN486 did not apparently affect efflux of $\left[{ }^{3} \mathrm{H}\right]$-paclitaxel in KB-3-1 cells (Figure 3B). However, the efflux activity was significantly decreased by RN486 in KB-C2 cells (Figure 3C). At the time point of $120 \mathrm{~min}$, comparing the concentration at $0 \mathrm{~min}$, the percentage of intracellular $\left[{ }^{3} \mathrm{H}\right]$-paclitaxel decreased to $16 \%$ in control group. For the treatment groups with 1, $3 \mu \mathrm{M}$ RN486, and $3 \mu \mathrm{M}$ verapamil, the percentage reduced to $45.76,49.87$, and $41.21 \%$, respectively. The results of high percentage of retained $\left[{ }^{3} \mathrm{H}\right]$-paclitaxel indicated that RN486 can interact with ABCB1 transporter and result in blocking the efflux activity of ABCB1overexpressing cell line. 
A

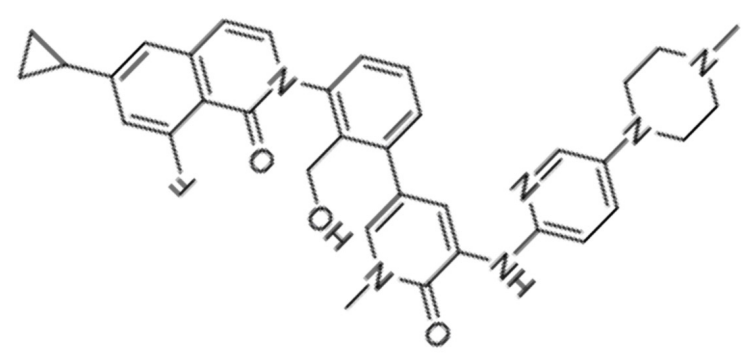

B

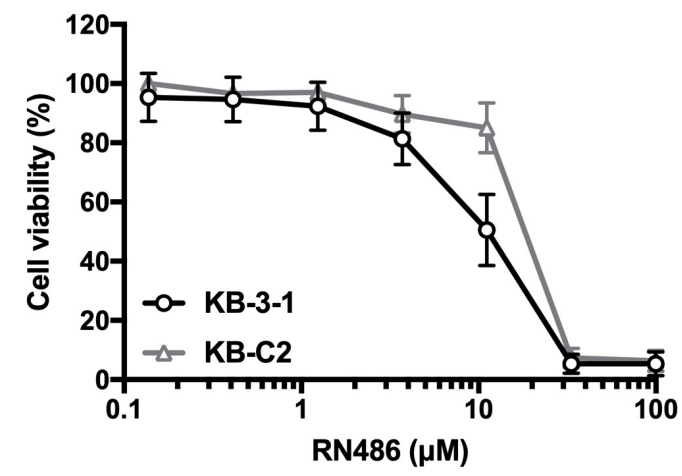

C

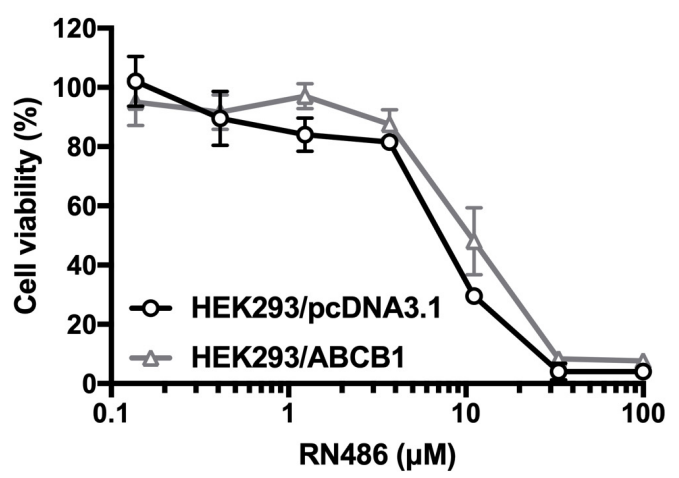

FIGURE 1 | Chemical structure of RN486 and cell viability curves in parental and drug-selected or ABCB1-transfected cancer cells administered with RN486. (A) Chemical structure of RN486. (B,C) Concentration-viability curves for KB-3-1, KB-C2, HEK293/pcDNA3.1, and HEK293/ABCB1 cells administered with RN486. Cytotoxicity of RN486 was determined by MTT assay. Dots with error bars in the image represent mean \pm SD with three independent assays.

TABLE 1 | The reversal effects of RN486 on ABCB1-mediated MDR in drug-selected resistant cells.

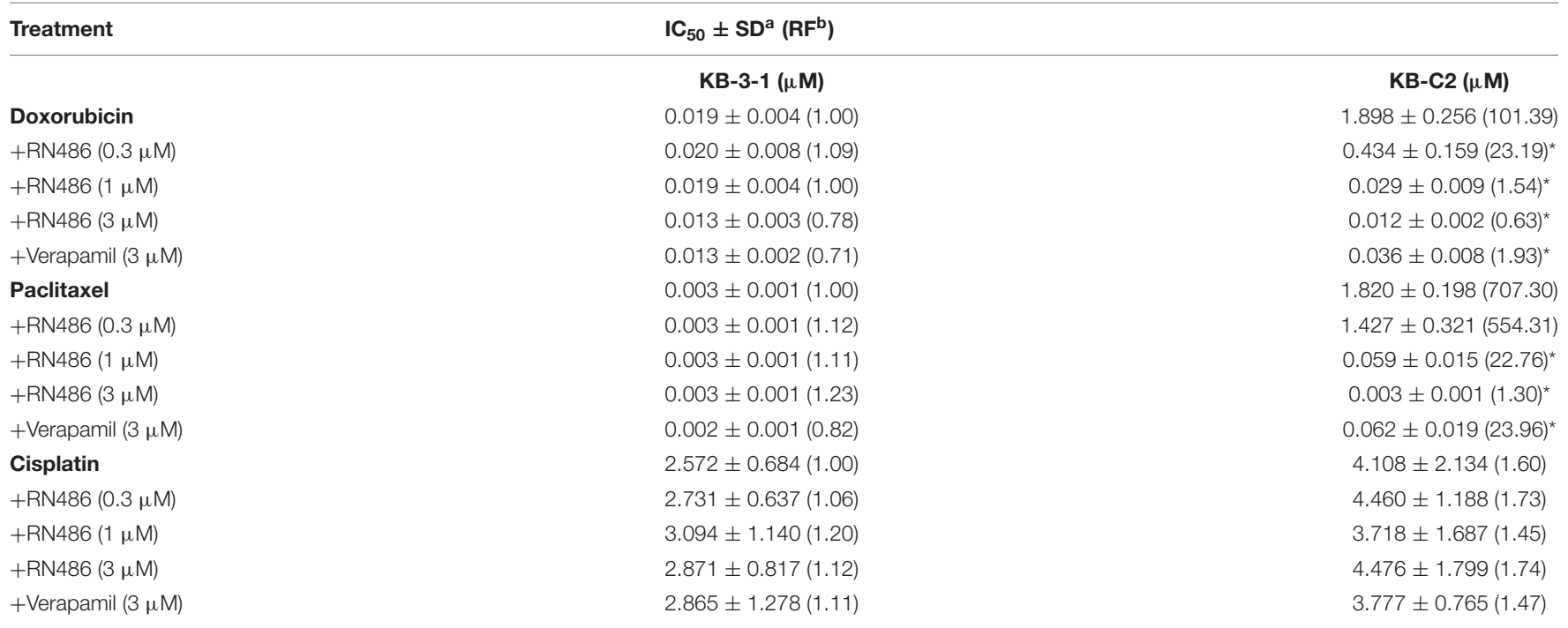

${ }^{a} C_{50}$ values represent mean \pm standard deviation (SD) acquired from at least three independent experiments. ${ }^{b}$ Resistance fold (RF) was calculated from dividing the $I_{50}$ values of parental or resistant cells in the presence or absence of RN486 or positive control inhibitor verapamil by the IC $C_{50}$ values of parental cells without reversal reagent. ${ }^{*} p<0.05$ versus control treatment in the absence of reversal reagent. 
TABLE 2 | The reversal effects of RN486 on ABCB1-mediated MDR in ABCB1-transfected cells.

\begin{tabular}{|c|c|c|}
\hline \multirow[t]{2}{*}{ Treatment } & \multicolumn{2}{|c|}{$I C_{50} \pm S D^{a}\left(R F^{b}\right)$} \\
\hline & HEK293/pcDNA3.1 ( $\mu$ M) & HEK293/АBCB1 ( $\mu$ M) \\
\hline Doxorubicin & $0.061 \pm 0.010(1.00)$ & $3.163 \pm 0.472(51.88)$ \\
\hline +RN486 (0.3 $\mu \mathrm{M})$ & $0.057 \pm 0.007(0.93)$ & $2.631 \pm 0.210(43.15)$ \\
\hline +RN486 (1 $\mu \mathrm{M})$ & $0.052 \pm 0.014(0.85)$ & $0.176 \pm 0.084(2.88)^{\star}$ \\
\hline +RN486 (3 $\mu \mathrm{M})$ & $0.048 \pm 0.003(0.79)$ & $0.066 \pm 0.018(1.08)^{*}$ \\
\hline +Verapamil (3 $\mu \mathrm{M})$ & $0.069 \pm 0.022(1.14)$ & $0.259 \pm 0.068(4.25)^{\star}$ \\
\hline Paclitaxel & $0.048 \pm 0.009(1.00)$ & $2.970 \pm 0.780(61.29)$ \\
\hline +RN486 (0.3 $\mu \mathrm{M})$ & $0.049 \pm 0.011(1.01)$ & $1.639 \pm 0.447(33.82)$ \\
\hline +RN486 (1 $\mu \mathrm{M})$ & $0.041 \pm 0.007(0.85)$ & $0.321 \pm 0.088(6.62)^{\star}$ \\
\hline +RN486 (3 $\mu \mathrm{M})$ & $0.037 \pm 0.005(0.77)$ & $0.040 \pm 0.021(1.13)^{\star}$ \\
\hline +Verapamil (3 $\mu \mathrm{M})$ & $0.040 \pm 0.004(0.82)$ & $0.303 \pm 0.057(6.25)^{\star}$ \\
\hline Cisplatin & $4.134 \pm 1.507(1.00)$ & $5.341 \pm 0.791(1.29)$ \\
\hline +RN486 (0.3 $\mu \mathrm{M})$ & $4.259 \pm 1.128(1.03)$ & $6.031 \pm 0.698(1.46)$ \\
\hline +RN486 (1 $\mu \mathrm{M})$ & $3.894 \pm 0.753(0.94)$ & $6.459 \pm 0.952(1.56)$ \\
\hline +RN486 (3 $\mu \mathrm{M})$ & $4.480 \pm 0.767(1.08)$ & $5.667 \pm 0.298(1.37)$ \\
\hline +Verapamil (3 $\mu \mathrm{M})$ & $4.415 \pm 1.955(1.07)$ & $4.693 \pm 0.497(1.14)$ \\
\hline
\end{tabular}

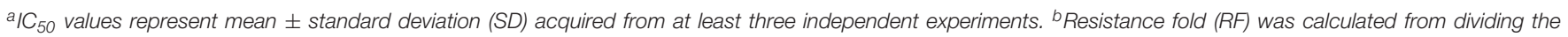

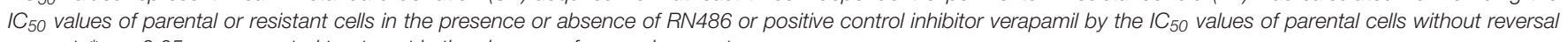
reagent. ${ }^{*} p<0.05$ versus control treatment in the absence of reversal reagent.

\section{The Effect of RN486 on ATPase Activity of ABCB1}

The energy used to efflux the substrate drugs of $\mathrm{ABCB} 1$ from the intracellular side to the extracellular side against the concentration gradient was provided by hydrolysis of ATP, which means the ATPase catalytic activity of ABCB1 transporter was of great significance. To further evaluate the effect of RN486 on the basal activity of $\mathrm{ABCB} 1 \mathrm{ATPase}$, different concentrations of RN486 $(0-40 \mu \mathrm{M})$ were incubated with the ABCB1-riched membranes using the ATPase assay kit. As shown in the results (Figure 4), no significant stimulatory or inhibitory impact was found by introducing lower concentrations of RN486, however, the stimulation effect of RN486 to ATPase activity of ABCB1 became boosted with higher concentrations of RN486, and the maximal stimulation reached up to $154 \%$ of basal activity. The stimulatory effect of RN486 on ABCB1 reached half-maximum $\left(\mathrm{EC}_{50}\right)$ at the concentration of $13 \mu \mathrm{M}$.

\section{Docking Simulation of RN486 in the Drug-Binding Pocket of Human ABCB1}

According to the ATPase assay result, RN486 showed stimulatory effect at higher concentrations. Consequently, we applied docking simulation in ATPase-stimulator (substrate) binding site of human $\mathrm{ABCB} 1$ protein (6QEX). The results showed that RN486 docked into the substrate site with an affinity score of $-9.5 \mathrm{kcal} / \mathrm{mol}$. Details of ligand-receptor interaction were displayed in Figures 5A-D. For the substrate-binding site, hydrophobic interactions played a crucial role in facilitating the binding of RN486 to the ABCB1 protein. RN486 was positioned and stabilized in the hydrophobic cavity formed by Ala229, Trp232, Phe303, Tyr307, Tyr310, Phe343, Asn721, Gln838, Asn842, Ala871, Glu875, and Gln946. Besides, the formation of hydrogen bond with Gln990 contributed to the stability of the hydroxide group of RN486 and the pyridine group of RN486 got stabilized by a formed hydrogen bond at Gln347. Additionally, RN486 didn't show significant stimulatory or inhibitory effects on ABCB1 ATPase at lower concentrations, which could be due to the counter-effect of stimulator and inhibitor. Therefore, we also performed docking simulation of RN486 and the ATPase inhibitor binding site of human ABCB1 (6QEE). The results showed that RN486 docked into the inhibitor binding site with an affinity score of $-9.1 \mathrm{kcal} / \mathrm{mol}$, which is similar to the score of substrate-binding complex. Details of ligand-receptor interaction were displayed in Figures 5E-H. For inhibitor binding site, hydrophobic interactions also played a key role in promoting the binding of RN486 to the ABCB1 protein. RN486 was positioned and stabilized in the hydrophobic cavity formed by Met68, Phe335, Phe982, Phe727, Ala986, Phe769, Phe993, Val990, Phe302, and Ile305. Moreover, the hydrogen bond formed with Gln724 made the hydroxide group of RN486 steady.

\section{DISCUSSION}

Overexpression of $\mathrm{ABC}$ transporter leading to MDR still remains a major barrier of successful chemotherapy (Chen et al., 2016; Amawi et al., 2019). ABCB1, as one of the most important $A B C$ transporters, is widely distributed in the body (Linton, 2007). The protective function of $A B C B 1$ transporter is to pump out xenobiotics. However, it could induce MDR if ABCB1 transporter gets overexpressed in tumor cells. The potential approach to improve the efficacy of chemotherapeutic drugs and overcome ABCB1-mediated MDR is the combination of reversal agents with anticancer drugs. Several studies showed the feasibility of small-molecule combination therapy. The reversal 
A

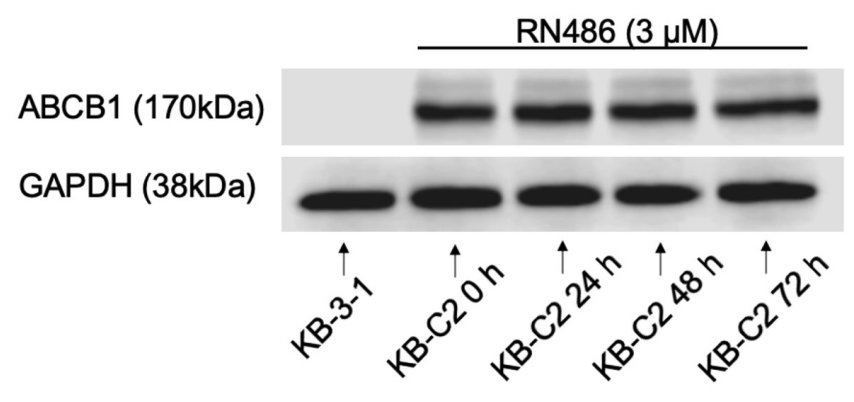

ns

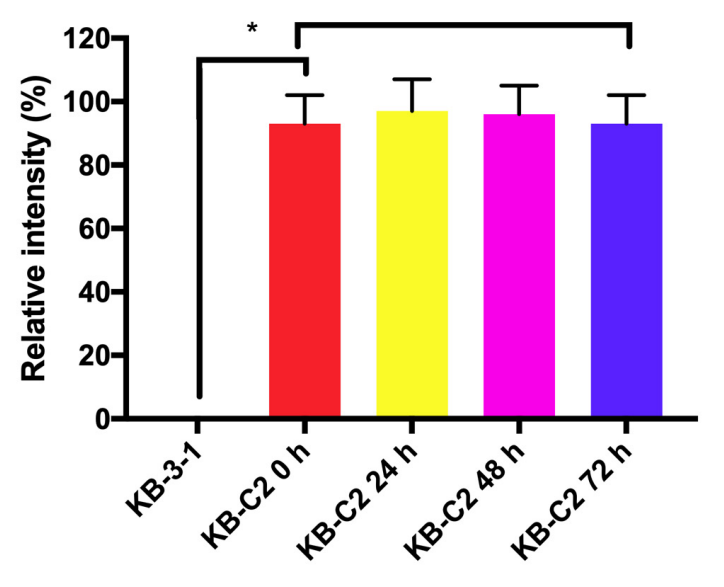

B

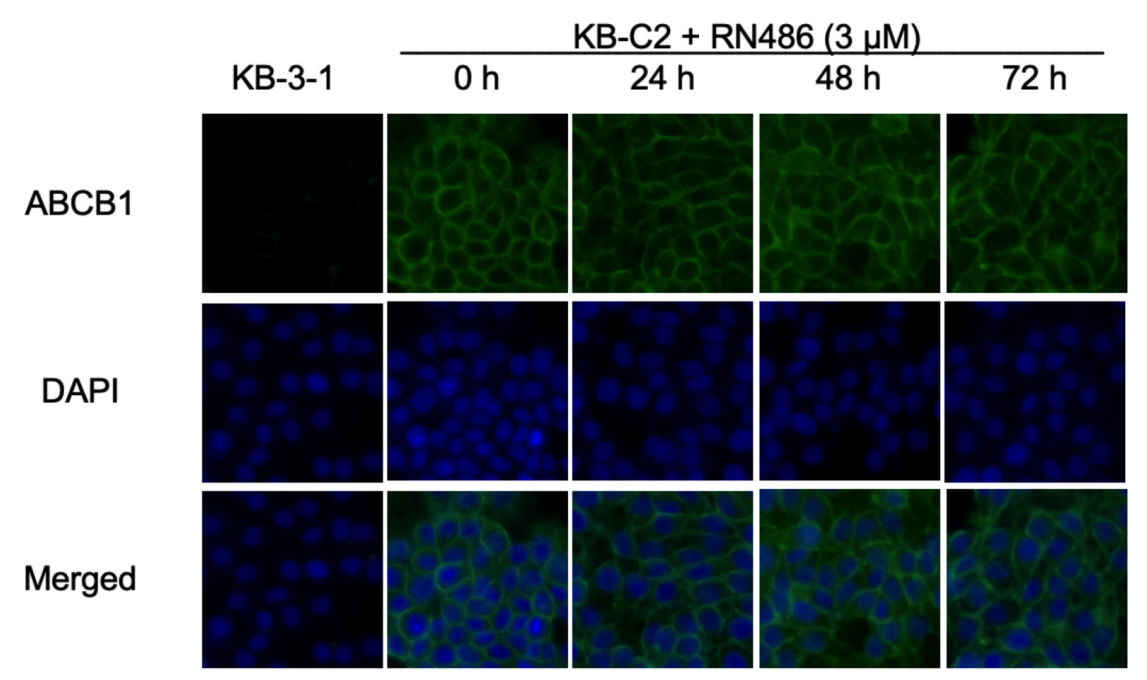

FIGURE 2 | RN486 did not change the protein expression and location of ABCB1. (A) ABCB1 expression level detected in KB-C2 cells with the treatment of $3 \mu \mathrm{M}$ RN486 for 0, 24, 48, and $72 \mathrm{~h}$. (B) Immunofluorescence on the subcellular localization of ABCB1 transporter with the treatment of $3 \mu \mathrm{M}$ RN486 for $0,24,48$, and $72 \mathrm{~h}$. Values are mean \pm SD, representative of three independent assays. KB-3-1 acts as control group. NS represents no significance.

agents including breakpoint cluster region-abelson (BCR-ABL) inhibitors imatinib (STI571) and ponatinib (Lei et al., 2006; Sen et al., 2012), epidermal growth factor receptor (EGFR) inhibitors lapatinib (GW-572016) and gefitinib (Kitazaki et al., 2005; Dai et al., 2008), vascular endothelial growth factor receptor (VEGFR) inhibitors vandetanib and motesanib (Zheng et al., 2009; Wang et al., 2014). However, although it was reported that ibrutinib could antagonize MDR mediated by ABCB1 (Zhang et al., 2017), 
A

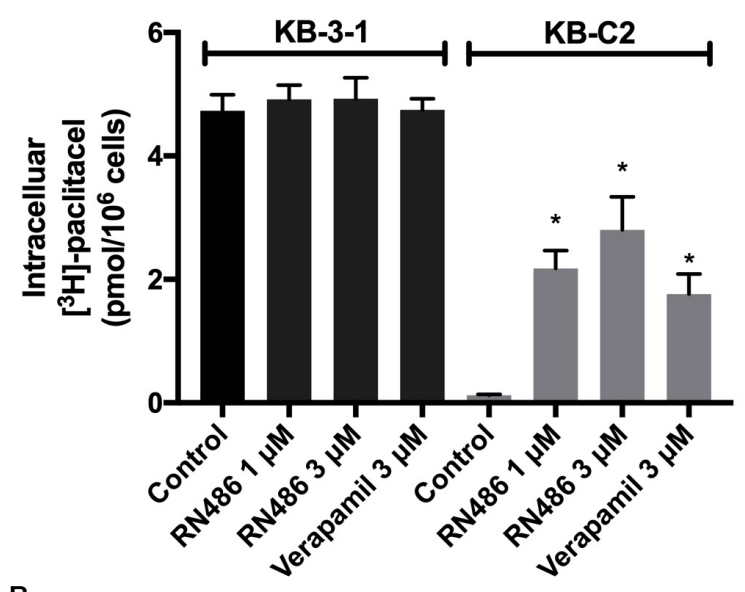

B

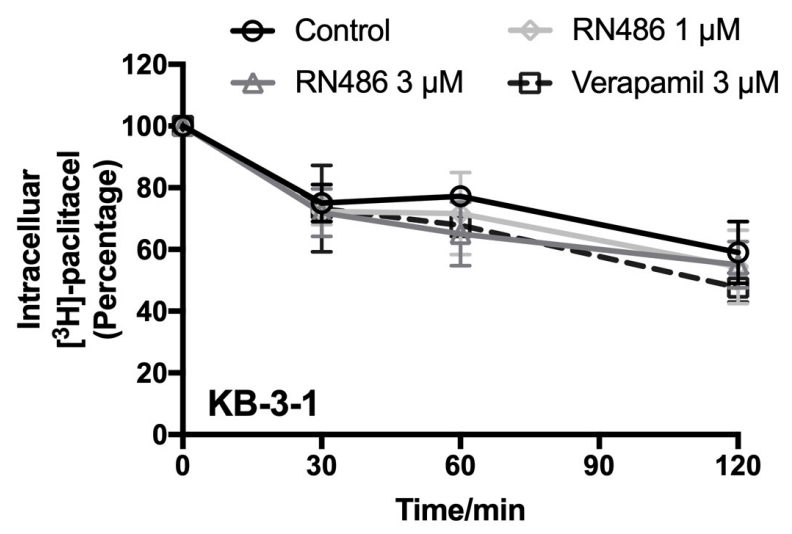

C

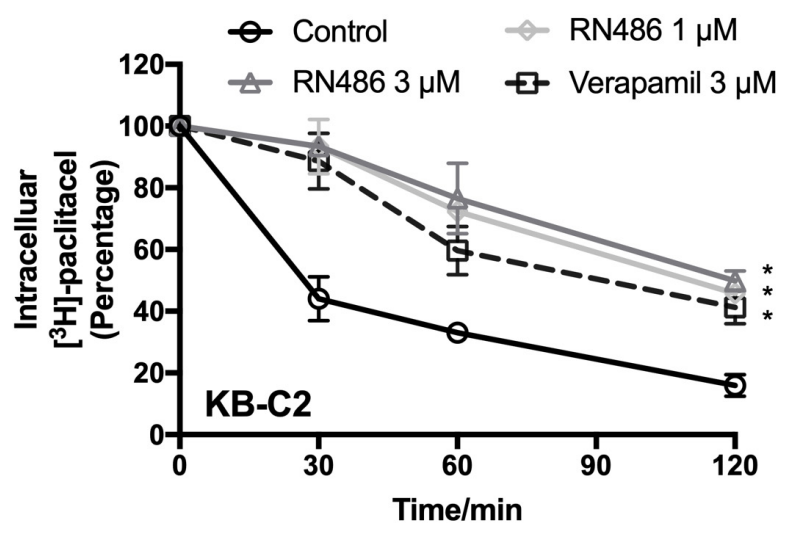

FIGURE 3 | Administered RN486 resulting in the increase of intracellular $\left[{ }^{3} \mathrm{H}\right]$-drug accumulation and the blockade of efflux activity of ABCB1 transporter in ABCB1-overexpressing cancer cells. (A) The effect of RN486 on the accumulation function of $\left[{ }^{3} \mathrm{H}\right]$-paclitaxel in ABCB1-mediated MDR cell lines. (B,C) The effects of RN486 on the efflux activity of $\left[{ }^{3} \mathrm{H}\right]$-paclitaxel in parental KB-3-1 and its drug-selected KB-C2 cells. Verapamil $(3 \mu \mathrm{M})$ was a positive control. Results shown as mean $\pm \mathrm{SD}$, three independent experiments were performed. ${ }^{\star} p<0.05$ versus control treatment. the study on other BTK inhibitors in reversing MDR mediated by $\mathrm{ABCB1-overexpression} \mathrm{is} \mathrm{still} \mathrm{lacking.}$

RN486 is a selective, and reversible inhibitor of BTK. As a preclinical drug, it has been reported to have satisfactory anti-inflammatory and bone-protective effects in rodents $\mathrm{Xu}$ et al., 2012). Several studies have shown that RN486 offers a novel attractive therapeutic alternative to the current RA therapy (Zhao et al., 2015a,b; Zhao et al., 2015c). However, there is no reports related to the antitumor effect of RN486 at present. Here we reported RN486 could surmount ABCB1-mediated MDR effectively in drug resistant cancer cells.

In this study, MTT assays were firstly designed to evaluate the possibility of cytotoxicity induced by RN486. According to the results, non-toxic concentrations $(0.3,1$, and $3 \mu \mathrm{M})$ of RN486 were selected in reversal experiments. Our data showed RN486, without interfering the parental KB-3-1 and HEK293/pcDNA3.1 cells, dramatically re-sensitized their resistant $\mathrm{KB}-\mathrm{C} 2$ and HEK293/ABCB1 cells to ABCB1 substrates paclitaxel and doxorubicin, which indicated the great reversal effect of RN486 in ABCB1-overexpressing cells. Furthermore, the reversal effect of $3 \mu \mathrm{M}$ RN486 was superior to the same concentration of positive control inhibitor of ABCB1 verapamil, suggesting that RN486 was more potent and effective than verapamil. Additionally, in the future, it is also valuable to evaluate the reversal effect of RN486 to other ABC transporters such as ABCG2 or ABCC1.

In order to get a better understanding of the reversal mechanism of RN486, Western blotting and immunofluorescence assay were carried out since the regulated expression and changed subcellular localization of $\mathrm{ABCB} 1$ transporter may happen after RN486 treatment. Our results suggested that RN486 did not affect the expression level of $\mathrm{ABCB} 1$ transporter in all resistant $\mathrm{KB}-\mathrm{C} 2$ cells treated with RN486 $(3 \mu \mathrm{M})$ up to $72 \mathrm{~h}$. Similar results were found in immunofluorescence assay. After incubation with RN486 (3 $\mu \mathrm{M})$ up to $72 \mathrm{~h}$, the ABCB1 transporter in resistant cells still located on the cell membrane without alteration. All these findings indicated that RN486 does not change expression level and subcellular localization of $\mathrm{ABCB} 1$ transporter. However, further experiments are warranted in the future to investigate the impact of longer treatment period or higher concentration of RN486 to $\mathrm{ABCB} 1$ transporter and also the effect of RN486 to other proteins that may be involved in the RN486 reversal mechanism.

Moreover, accumulation and efflux assays were conducted to have a better understanding of the antagonized function of RN486 to ABCB1-mediated MDR. Based on our results, in $\mathrm{ABCB} 1$-overexpressing $\mathrm{KB}-\mathrm{C} 2$ cells, intracellular substrate concentration was dramatically increased by incubated with RN486 in the accumulation assay and the efflux function of ABCB1 was blocked by RN486. Nevertheless, RN486 has no effect on parental KB-3-1 cells. These results were consistent with our reversal studies, which RN486 has significant effect on reversing $\mathrm{ABCB} 1$-mediated MDR. The results also illustrate that by inhibiting transporter efflux activity, co-administered RN486 increases intracellular accumulation of substrate which enhances the efficacy of chemotherapy.

Energy supplemented by ATP hydrolysis plays an important role in the activity of $\mathrm{ABCB} 1$ transporter. The substrates or 


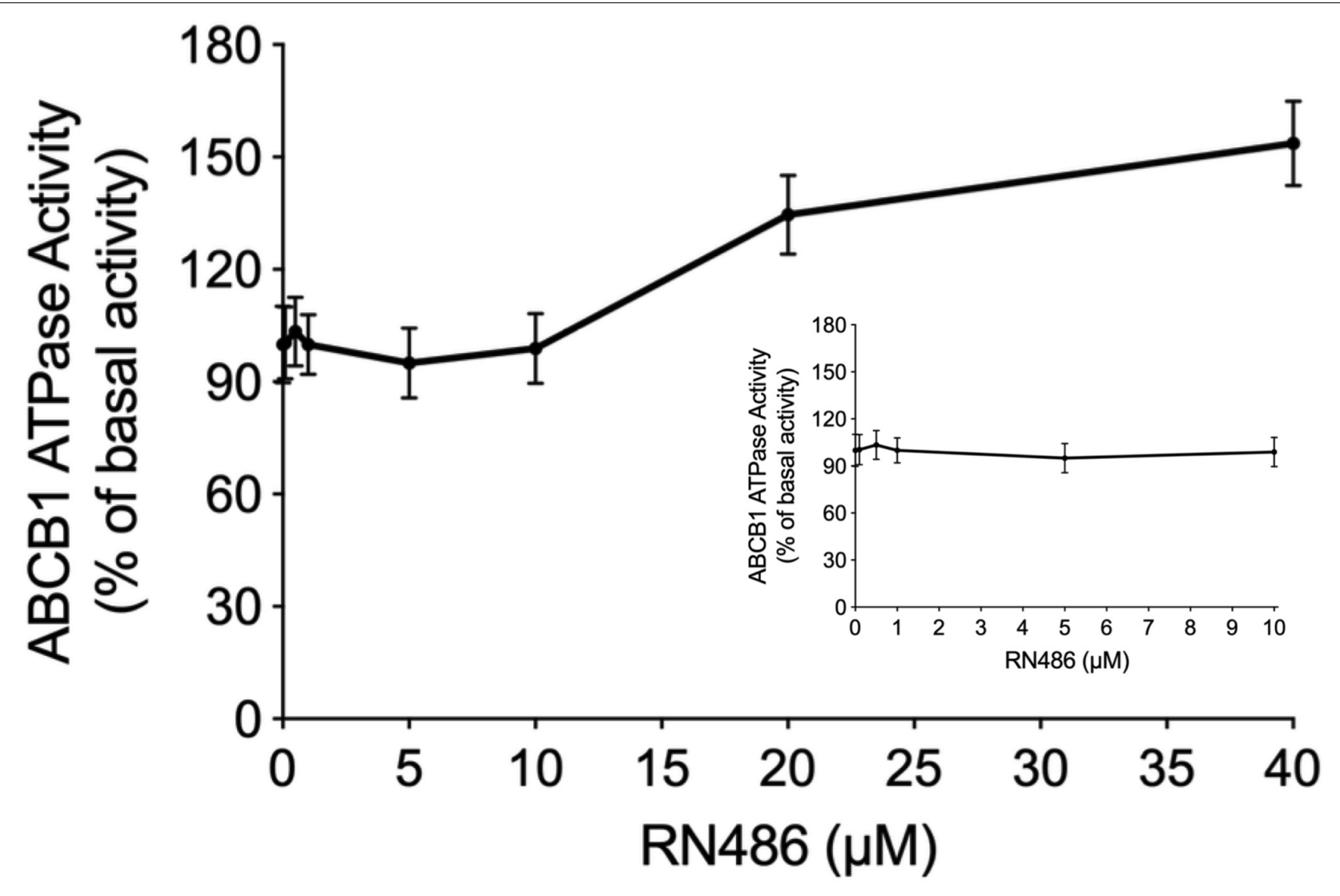

FIGURE 4 | The effect of RN486 on the ATPase activity of ABCB1. Different concentrations (0-40 $\mu$ M) of RN486 affected the ATP hydrolysis process, which mediated by ATPase of ABCB1. The inset graph demonstrates the effect of 0-10 $\mu \mathrm{M}$ RN486 on the ATPase activity of ABCB1. Data are mean \pm SD of three independent assays.

inhibitors of ABCB1 transporter may affect ATPase activity (Zhang et al., 2018; Ji et al., 2019a). The decreased trend of ATPase activity would be observed when the drug serves as an ATPase inhibitor since it inhibits the function of ABCB1 transporter, however, the substrate would stimulate the ATPase at substrate-binding site which provides energy to facilitate drug efflux. Thus, we performed ATPase assay to evaluate the effect of RN486 on ATPase function of ABCB1. From our results, the ATP hydrolysis of $\mathrm{ABCB} 1$ was less affected when the concentrations of RN486 was lower, but higher concentrations of RN486 exhibited the distinct stimulatory effect on ATPase of ABCB1 in a dose-dependent manner with a maximal level of 1.54 -fold. These results suggested that RN486 neither stimulate nor inhibit the ATPase activity at lower concentrations. However, RN486 with higher concentrations may bind substrate-binding site of $A B C B 1$, which granted its stimulatory effect on ATPase activity of $\mathrm{ABCB} 1$. It should be noted that some of $\mathrm{ABC}$ transporter substrate-drugs could competitively occupy the substrate-binding site resulting in inhibited efflux of certain substrates (Giri et al., 2009). RN486 may act on ABCB1 with the same mechanism. Furthermore, the cytotoxicity experiments excluded RN486 is a substrate of ABCB1. In addition, even though some ABCB1 inhibitors were identified as stimulators in ATPase assay of ABCB1, ABCB1 overexpression might not necessarily cause drug resistance to those inhibitors (Cui et al., 2019a; Wu et al., 2020). The reasons for unchanged ATPase activity with 0-10 $\mu \mathrm{M}$ RN486 may vary included additional interactions between RN486 with inhibitor binding site. As a wide-ranging used technique in structural molecular biology, the molecular docking study was carried out to further investigate the affinity of RN486 to the ABCB1 substrate and inhibitor binding sites. The results indicated that RN486 has high affinity to both transmembrane ATPase-stimulator (substrate) binding site and inhibitor binding site with the affinity score of -9.5 and $-9.1 \mathrm{kcal} / \mathrm{mol}$. Hydrophobic interactions between RN486 and ABCB1 protein contributed to the stability of RN486 to the hydrophobic cavity. Unlike erdafitinib (Feng et al., 2020) and MK-8776 (Cui et al., 2019b), RN486 preferred to bind both substrate-binding site and inhibitor binding site which indicated more complicated conformation changes emerged in the interaction of RN486 with human ABCB1 model. At the substrate-binding pocket of ABCB1 transporter, RN486 may supersede other anti-cancer drugs that are substrates of ABCB1 resulting in stimulation of ATPase activity. This binding may always exist and was dominant at higher concentrations of RN486. When the concentration of RN486 was lower, the binding 

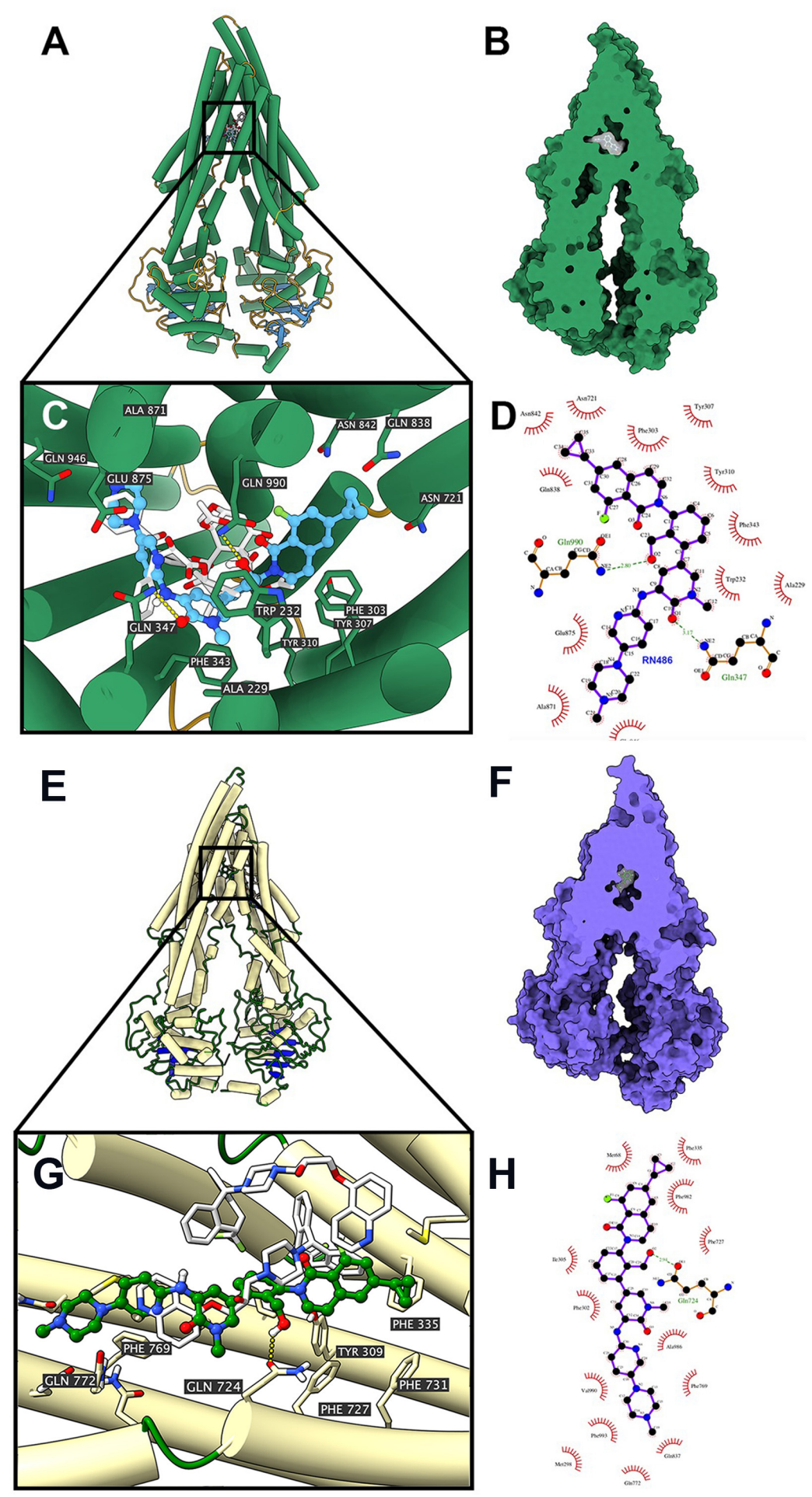

FIGURE 5 | Interaction between RN486 and human ABCB1 protein. (A) Overview of paclitaxel and the best-scoring pose of RN486 in the drug-binding pocket of ABCB1 protein (6QEX). ABCB1 was displayed as colored tubes and ribbons. RN486 and paclitaxel were displayed as colored sticks. Carbon: blue (RN486) or white (paclitaxel); oxygen: red; nitrogen: blue; fluoride: green. (B) Interactions between RN486 and ABCB1 binding pocket with the protein surface of ABCB1 displayed. (C) Details of interactions between RN486 and ABCB1 binding pocket. Hydrogen bonds were displayed as yellow dash lines. (D) 2D RN486-ABCB1 interaction. Important amino acids were displayed as red arcs, and the green dash line with number indicates hydrogen bond with bond length. Carbon: black; oxygen: red; nitrogen: blue; fluoride: green. (E) Overview of zosuquidar and the best-scoring pose of RN486 in the drug-binding pocket of ABCB1 protein (6QEE). ABCB1 was displayed as colored tubes and ribbons. RN486 and zosuquidar were displayed as colored sticks. Carbon: green (RN486) or white (zosuquidar); oxygen: red; nitrogen: blue; fluoride: light green. (F) Interactions between RN486 and ABCB1 binding pocket with protein surface of ABCB1 displayed. (G) Details of interactions between RN486 and ABCB1 binding pocket. Hydrogen bonds were displayed as yellow dash lines. (H) 2D RN486-ABCB1 interaction. Color codes are same as (D). 
of RN486 with inhibitor binding site probably also presented which restrained the activity of ATPase, the stimulatory and inhibitory effects of RN486 were neutralized, which in turn interpreted the flat curve of ATPase activity with $0-10 \mu \mathrm{M}$ RN486 (Figure 4). In addition, both binding interactions between RN486 and human ABCB1 protein worked in blocking the efflux of anti-cancer drugs from $\mathrm{ABCB} 1$, which leading to the increased intracellular concentration of chemotherapeutic drugs like paclitaxel and rendering RN486 of potential reversal effect.

In conclusion, this study elucidated that the reversal mechanism of RN486 to ABCB1-mediated MDR is to inhibit anti-cancer drugs being pumped out by ABCB1 transporter without obstructing the expression and subcellular localization of ABCB1 protein. The ATPase assay and molecular docking study offered more details about possible interactions between RN486 and ABCB1 protein. Future studies may focus on other mechanisms of action of RN486 to ABCB1 transporter and in vivo tumor xenograft model. The combination therapy using RN486 with ABCB1 substrate chemotherapeutic drugs may offer an alternative approach to overcome ABCB1-mediated MDR.

\section{DATA AVAILABILITY STATEMENT}

All datasets presented in this study are included in the article/supplementary material.

\section{REFERENCES}

Alam, A., Kowal, J., Broude, E., Roninson, I., and Locher, K. P. (2019). Structural insight into substrate and inhibitor discrimination by human P-glycoprotein. Science 363, 753-756. doi: 10.1126/science.aav7102

Amawi, H., Sim, H.-M., Tiwari, A. K., Ambudkar, S. V., and Shukla, S. (2019). “ABC transporter-mediated multidrug-resistant cancer," in Drug Transporters in Drug Disposition, Effects and Toxicity. Advances in Experimental Medicine and Biology, Vol. 1141, eds X. Liu and G. Pan (Singapore: Springer), 549-580.

Cai, C.-Y., Zhang, W., Wang, J.-Q., Lei, Z.-N., Zhang, Y.-K., Wang, Y.-J., et al. (2020). Biological evaluation of non-basic chalcone CYB-2 as a dual ABCG2/ABCB1 inhibitor. Biochem. Pharmacol. 175:113848. doi: 10.1016/j.bcp. 2020.113848

Chen, Z., Shi, T., Zhang, L., Zhu, P., Deng, M., Huang, C., et al. (2016). Mammalian drug efflux transporters of the ATP binding cassette $(\mathrm{ABC})$ family in multidrug resistance: a review of the past decade. Cancer Lett. 370, 153-164. doi: 10.1016/ j.canlet.2015.10.010

Cui, Q., Cai, C.-Y., Gao, H.-L., Ren, L., Ji, N., Gupta, P., et al. (2019a). Glesatinib, a c-MET/SMO dual inhibitor, antagonizes P-glycoprotein mediated multidrug resistance in cancer cells. Front. Oncol. 9:313. doi: 10.3389/fonc.2020.00313

Cui, Q., Cai, C.-Y., Wang, J.-Q., Zhang, S., Gupta, P., Ji, N., et al. (2019b). Chk1 inhibitor MK-8776 restores the sensitivity of chemotherapeutics in p-glycoprotein overexpressing cancer cells. Intern. J. Mol. Sci. 20:4095. doi: 10.3390/ijms20174095

Dai, C.-L., Tiwari, A. K., Wu, C.-P., Su, X.-D., Wang, S.-R., Liu, D.-G., et al. (2008). Lapatinib (Tykerb, GW572016) reverses multidrug resistance in cancer cells by inhibiting the activity of ATP-binding cassette subfamily B member 1 and G member 2. Cancer Res. 68, 7905-7914. doi: 10.1158/0008-5472.can-08-0499

Dassa, E., and Bouige, P. (2001). The ABC of ABCs: a phylogenetic and functional classification of ABC systems in living organisms. Res. Microbiol. 152, 211-229. doi: 10.1016/s0923-2508(01)01194-9

Dean, M. (2009). ABC transporters, drug resistance, and cancer stem cells. J. Mamm. Gland Biol. Neoplasia 14, 3-9. doi: 10.1007/s10911-0099109-9

\section{AUTHOR CONTRIBUTIONS}

Z-SC, LL, and WF designed the experiments. X-DD wrote the original draft manuscript. Z-NL and Q-XT reviewed the manuscript. X-DD, MZ, WF, J-QW, Z-NL, Q-XT, Y-DL, and XM performed the experiments. WF and LL analyzed the data. Z-SC and WF edited the manuscript. All authors discussed the data and approved the final manuscript.

\section{FUNDING}

This work was supported by the Medical and Health Development Plan of Shandong Province (2017WS058) and Research and Development Plan of University in Shandong Province (J18KA120).

\section{ACKNOWLEDGMENTS}

We would like to thank Chemie Tek (Indianapolis, IN) for kindly offering RN486 chemical. We would like to thank Dr. Shin-Ichi Akiyama (Kagoshima University, Kagoshima, Japan) for offering the KB-3-1 and KB-C2 cell lines. We would like to thank Drs. Susan Bates and Robert Robey (NCI, NIH, MD) for providing HEK293/pcDNA3.1 and ABCB1-transfected HEK/ABCB1 cell lines.

Eckford, P. D., and Sharom, F. J. (2009). ABC efflux pump-based resistance to chemotherapy drugs. Chem. Rev. 109, 2989-3011. doi: 10.1021/cr9000226

Fan, Y.-F., Zhang, W., Zeng, L., Lei, Z.-N., Cai, C.-Y., Gupta, P., et al. (2018). Dacomitinib antagonizes multidrug resistance (MDR) in cancer cells by inhibiting the efflux activity of ABCB1 and ABCG2 transporters. Cancer Lett. 421, 186-198. doi: 10.1016/j.canlet.2018.01.021

Feng, W., Zhang, M., Wu, Z.-X., Wang, J.-Q., Dong, X.-D., Yang, Y., et al. (2020). Erdafitinib antagonizes ABCB1-mediated multidrug resistance in cancer cells. Front. Oncol. 10:955. doi: 10.3389/fonc.2020.00955

Gavriatopoulou, M., Fotiou, D., Ntanasis-Stathopoulos, I., and Dimopoulos, M. A. (2020). The current role of BTK inhibitors in the treatment of Waldenstrom's Macroglobulinemia. Expert Rev. Anticancer Ther. 1-12. doi: 10.1080/14737140. 2020.1791705 [Epub ahead of print].

Giri, N., Agarwal, S., Shaik, N., Pan, G., Chen, Y., and Elmquist, W. F. (2009). Substrate-dependent breast cancer resistance protein (Bcrp1/Abcg2)-mediated interactions: consideration of multiple binding sites in in vitro assay design. Drug Metab. Disposit. 37, 560-570. doi: 10.1124/dmd.108.022046

Gottesman, M. M., Fojo, T., and Bates, S. E. (2002). Multidrug resistance in cancer: role of ATP-dependent transporters. Nat. Rev. Cancer 2, 48-58. doi: 10.1038/ nrc706

Guo, W., Liu, R., Bhardwaj, G., Yang, J., Changou, C., Ma, A., et al. (2014). Targeting Btk/Etk of prostate cancer cells by a novel dual inhibitor. Cell Death Dis. 5:e1409. doi: 10.1038/cddis.2014.343

Hartkamp, L. M., Fine, J. S., Van Es, I. E., Tang, M. W., Smith, M., Woods, J., et al. (2015). Btk inhibition suppresses agonist-induced human macrophage activation and inflammatory gene expression in RA synovial tissue explants. Ann. Rheum. Dis. 74, 1603-1611. doi: 10.1136/annrheumdis-2013-204143

Ji, N., Yang, Y., Cai, C.-Y., Lei, Z.-N., Wang, J.-Q., Gupta, P., et al. (2019a). Selonsertib (GS-4997), an ASK1 inhibitor, antagonizes multidrug resistance in ABCB1-and ABCG2-overexpressing cancer cells. Cancer Lett. 440, 82-93. doi: 10.1016/j.canlet.2018.10.007

Ji, N., Yang, Y., Cai, C.-Y., Wang, J.-Q., Lei, Z.-N., Wu, Z.-X., et al. (2019b). Midostaurin reverses ABCB1-mediated multidrug resistance, an in vitro study. Front. Oncol. 9:514. doi: 10.3389/fonc.2019.00514 
Juliano, R. L., and Ling, V. (1976). A surface glycoprotein modulating drug permeability in Chinese hamster ovary cell mutants. Biochim. Biophys. Acta Biomembr. 455, 152-162. doi: 10.1016/0005-2736(76)90160-7

Kartal-Yandim, M., Adan-Gokbulut, A., and Baran, Y. (2016). Molecular mechanisms of drug resistance and its reversal in cancer. Crit. Rev. Biotechnol. $36,716-726$.

Kathawala, R. J., Gupta, P., Ashby, C. R. Jr., and Chen, Z.-S. (2015a). The modulation of $\mathrm{ABC}$ transporter-mediated multidrug resistance in cancer: a review of the past decade. Drug Resist. Updates 18, 1-17. doi: 10.1016/j.drup. 2014.11.002

Kathawala, R. J., Wei, L., Anreddy, N., Chen, K., Patel, A., Alqahtani, S., et al. (2015b). The small molecule tyrosine kinase inhibitor NVPBHG712 antagonizes ABCC10-mediated paclitaxel resistance: a preclinical and pharmacokinetic study. Oncotarget 6:510. doi: 10.18632/oncotarget.2638

Kitazaki, T., Oka, M., Nakamura, Y., Tsurutani, J., Doi, S., Yasunaga, M., et al. (2005). Gefitinib, an EGFR tyrosine kinase inhibitor, directly inhibits the function of P-glycoprotein in multidrug resistant cancer cells. Lung Cancer 49, 337-343. doi: 10.1016/j.lungcan.2005.03.035

Lei, G., Li, C., Fei, X.-H., Qiu, H.-Y., Hong, Z., and Wang, J.-M. (2006). STI571 combined with vincristine greatly suppressed the tumor formation of multidrug-resistant K562 cells in a human-nude mice xenograft model. Chin. Med. J. 119, 911-918. doi: 10.1097/00029330-200606010-00006

Li, W., Zhang, H., Assaraf, Y. G., Zhao, K., Xu, X., Xie, J., et al. (2016). Overcoming $\mathrm{ABC}$ transporter-mediated multidrug resistance: molecular mechanisms and novel therapeutic drug strategies. Drug Resist. Updates 27, 14-29. doi: 10.1016/ j.drup.2016.05.001

Linton, K. J. (2007). Structure and function of ABC transporters. Physiology 22, 122-130. doi: 10.1152/physiol.00046.2006

Lyall, R. M., Hwang, J., Cardarelli, C., Fitzgerald, D., Akiyama, S.-I., Gottesman, M. M., et al. (1987). Isolation of human KB cell lines resistant to epidermal growth factor-Pseudomonas exotoxin conjugates. Cancer Res. 47, 2961-2966.

Metzler, J. M., Burla, L., Fink, D., and Imesch, P. (2020). Ibrutinib in gynecological malignancies and breast cancer: a systematic review. Intern. J. Mol. Sci. 21:4154. doi: 10.3390/ijms21114154

Mina-Osorio, P., Lastant, J., Keirstead, N., Whittard, T., Ayala, J., Stefanova, S., et al. (2013). Suppression of glomerulonephritis in lupus-prone NZB $\times N Z W$ mice by RN486, a selective inhibitor of Bruton's tyrosine kinase. Arthrit. Rheum. 65, 2380-2391. doi: 10.1002/art.38047

Mohamed, A. J., Yu, L., Bäckesjö, C. M., Vargas, L., Faryal, R., Aints, A., et al. (2009). Bruton's tyrosine kinase (Btk): function, regulation, and transformation with special emphasis on the PH domain. Immunol. Rev. 228, 58-73. doi: 10.1111/j.1600-065x.2008.00741.x

Pikatan, N. W., Liu, Y.-L., Bamodu, O. A., Hsiao, M., Hsu, W.-M., Haryana, S. M., et al. (2020). Aberrantly expressed Bruton's tyrosine kinase preferentially drives metastatic and stem cell-like phenotypes in neuroblastoma cells. Cell. Oncol. 1-18. doi: 10.1007/s13402-020-00541-5 [Epub ahead of print].

Rathi, A. K., Syed, R., Singh, V., Shin, H. S., and Patel, R. V. (2017). Kinase inhibitor indole derivatives as anticancer agents: a patent review. Recent Pat. Anticancer Drug Discov. 12, 55-72. doi: 10.2174/1574892811666161003112119

Roy, P., and Saikia, B. (2016). Cancer and cure: a critical analysis. Indian J. Cancer 53:441.

Schinkel, A. H. (1999). P-Glycoprotein, a gatekeeper in the blood-brain barrier. Adv. Drug Deliver. Rev. 36, 179-194. doi: 10.1016/s0169-409x(98)00085-4

Schinkel, A. H., and Jonker, J. W. (2012). Mammalian drug efflux transporters of the ATP binding cassette (ABC) family: an overview. Adv. Drug Deliver. Rev. 64, 138-153. doi: 10.1016/j.addr.2012.09.027

Sen, R., Natarajan, K., Bhullar, J., Shukla, S., Fang, H.-B., Cai, L., et al. (2012). The novel BCR-ABL and FLT3 inhibitor ponatinib is a potent inhibitor of the MDRassociated ATP-binding cassette transporter ABCG2. Mol. Cancer Therap. 11, 2033-2044. doi: 10.1158/1535-7163.mct-12-0302

Singh, S. P., Dammeijer, F., and Hendriks, R. W. (2018). Role of Bruton's tyrosine kinase in B cells and malignancies. Mol. Cancer 17:57.

Sodani, K., Patel, A., Kathawala, R. J., and Chen, Z.-S. (2012). Multidrug resistance associated proteins in multidrug resistance. Chin. J. Cancer 31:58. doi: 10.5732/ cjc.011.10329

Sparreboom, A., Van Asperen, J., Mayer, U., Schinkel, A. H., Smit, J. W., Meijer, D. K., et al. (1997). Limited oral bioavailability and active epithelial excretion of paclitaxel (Taxol) caused by P-glycoprotein in the intestine. Proc. Natl. Acad. Sci. U.S.A. 94, 2031-2035. doi: 10.1073/pnas.94.5.2031
Stavrovskaya, A., and Stromskaya, T. (2008). Transport proteins of the ABC family and multidrug resistance of tumor cells. Biochemistry 73, 592-604. doi: 10.1134/ s0006297908050118

Tiwari, A. K., Sodani, K., Dai, C.-L., Ashby, C. R., and Chen, Z.-S. (2011). Revisiting the ABCs of multidrug resistance in cancer chemotherapy. Curr. Pharm. Biotechnol. 12, 570-594. doi: 10.2174/138920111795164048

Vina, A. (2010). Improving the speed and accuracy of docking with a new scoring function, efficient optimization, and multithreading Trott, Oleg; Olson, Arthur. J. Comput. Chem. 31, 455-461.

Wang, J., Yang, D.-H., Yang, Y., Wang, J.-Q., Cai, C.-Y., Lei, Z.-N., et al. (2020). Overexpression of ABCB1 transporter confers resistance to mTOR inhibitor WYE-354 in cancer cells. Intern. J. Mol. Sci. 21:1387. doi: 10.3390/ijms21041387

Wang, J.-Q., Li, J. Y., Teng, Q.-X., Lei, Z.-N., Ji, N., Cui, Q., et al. (2020). Venetoclax, a BCL-2 inhibitor, enhances the efficacy of chemotherapeutic agents in wildtype ABCG2-overexpression-mediated MDR cancer cells. Cancers 12:466. doi: $10.3390 /$ cancers 12020466

Wang, Y.-J., Kathawala, R. J., Zhang, Y.-K., Patel, A., Kumar, P., Shukla, S., et al. (2014). Motesanib (AMG706), a potent multikinase inhibitor, antagonizes multidrug resistance by inhibiting the efflux activity of the ABCB1. Biochem. Pharmacol. 90, 367-378. doi: 10.1016/j.bcp.2014.06.006

Wu, C.-P., Hsieh, C.-H., and Wu, Y.-S. (2011). The emergence of drug transportermediated multidrug resistance to cancer chemotherapy. Mol. Pharm. 8, 19962011. doi: $10.1021 / \mathrm{mp} 200261 \mathrm{n}$

Wu, C.-P., Lusvarghi, S., Wang, J.-C., Hsiao, S.-H., Huang, Y.-H., Hung, T.H., et al. (2020). The selective class IIa histone deacetylase inhibitor TMP195 resensitizes $\mathrm{ABCB} 1$-and $\mathrm{ABCG} 2$-overexpressing multidrug-resistant cancer cells to cytotoxic anticancer drugs. Intern. J. Mol. Sci. 21:238. doi: 10.3390/ ijms21010238

Xu, D., Kim, Y., Postelnek, J., Vu, M. D., Hu, D.-Q., Liao, C., et al. (2012). RN486, a selective Bruton's tyrosine kinase inhibitor, abrogates immune hypersensitivity responses and arthritis in rodents. J. Pharmacol. Exper. Therap. 341, 90-103. doi: 10.1124/jpet.111.187740

Zhang, G.-N., Zhang, Y.-K., Wang, Y.-J., Gupta, P., Ashby, C. R. Jr., Alqahtani, S., et al. (2018). Epidermal growth factor receptor (EGFR) inhibitor PD153035 reverses ABCG2-mediated multidrug resistance in non-small cell lung cancer: in vitro and in vivo. Cancer Lett. 424, 19-29. doi: 10.1016/j.canlet.2018.02.040

Zhang, H., Patel, A., Wang, Y.-J., Zhang, Y.-K., Kathawala, R. J., Qiu, L.-H., et al. (2017). The BTK inhibitor ibrutinib (PCI-32765) overcomes paclitaxel resistance in ABCB1-and ABCC10-overexpressing cells and tumors. Mol. Cancer Therap. 16, 1021-1030. doi: 10.1158/1535-7163.mct-16-0511

Zhang, Y.-K., Wang, Y.-J., Gupta, P., and Chen, Z.-S. (2015). Multidrug resistance proteins (MRPs) and cancer therapy. AAPS J. 17, 802-812. doi: 10.1208/ s12248-015-9757-1

Zhao, X., Huang, W., Wang, Y., Xin, M., Jin, Q., Cai, J., et al. (2015a). Discovery of novel Bruton's tyrosine kinase (BTK) inhibitors bearing a pyrrolo [2, 3-d] pyrimidine scaffold. Bioorgan. Med. Chem. 23, 891-901.

Zhao, X., Huang, W., Wang, Y., Xin, M., Jin, Q., Cai, J., et al. (2015b). Pyrrolo [2, 3-b] pyridine derivatives as potent Bruton's tyrosine kinase inhibitors. Bioorgan. Med. Chem. 23, 4344-4353.

Zhao, X., Xin, M., Huang, W., Ren, Y., Jin, Q., Tang, F., et al. (2015c). Design, synthesis and evaluation of novel 5-phenylpyridin-2 $(1 \mathrm{H})$-one derivatives as potent reversible Bruton's tyrosine kinase inhibitors. Bioorgan. Med. Chem. 23, 348-364.

Zheng, L.-S., Wang, F., Li, Y.-H., Zhang, X., Chen, L.-M., Liang, Y.-J., et al. (2009). Vandetanib (Zactima, ZD6474) antagonizes ABCC1-and ABCG2-mediated multidrug resistance by inhibition of their transport function. PLoS One 4:e5172. doi: 10.1371/journal.pone.0005172

Conflict of Interest: The authors declare that the research was conducted in the absence of any commercial or financial relationships that could be construed as a potential conflict of interest.

Copyright (c) 2020 Dong, Zhang, Ma, Wang, Lei, Teng, Li, Lin, Feng and Chen. This is an open-access article distributed under the terms of the Creative Commons Attribution License (CC BY). The use, distribution or reproduction in other forums is permitted, provided the original author(s) and the copyright owner(s) are credited and that the original publication in this journal is cited, in accordance with accepted academic practice. No use, distribution or reproduction is permitted which does not comply with these terms. 